\title{
Preparation method and growth factor content of platelet concentrate influence the osteogenic differentiation of bone marrow stromal cells
}

\author{
FRANCESCA PERUT ${ }^{1}$, GIUSEPPE FILARDO ${ }^{2}$, ERMINIA MARIANI $^{3,4}$, \\ ANNARITA CENACCHI ${ }^{5}$, LOREDANA PRATELLI ${ }^{6}$, VALENTINA DEVESCOVI ${ }^{1}$, \\ ELIZAVETA KON ${ }^{2}$, MAURILIO MARCACCI ${ }^{2}$, ANDREA FACCHINI ${ }^{3,4}$, \\ NICOLA BALDINI ${ }^{1,7}$ \& DONATELLA GRANCHI ${ }^{1}$
}

${ }^{1}$ Laboratory for Orthopaedic Pathophysiology and Regenerative Medicine, ${ }^{2}$ Laboratory of Biomechanics and Technology Innovation, ${ }^{3}$ Laboratory of Immunorheumatology and Tissue Regeneration, and ${ }^{6}$ Clinical Pathology Unit, Rizzoli Orthopedic Institute, Bologna, Italy, ${ }^{5}$ Immunohematology and Transfusion Medicine and Cell and Musculoskeletal Tissue Bank, Bologna, Italy, and ${ }^{4}$ Department of Clinical Medicine and ${ }^{7}$ Department of Biomedical and Neuromotion Sciences, University of Bologna, Bologna, Italy

\begin{abstract}
Background aims. An extensive debate about the clinical benefits of autologous platelet concentrates used as a treatment option for patients with orthopedic injuries is ongoing. The aim of this study was to determine whether different compositions of platelet concentrates may affect the osteogenic differentiation of bone marrow stromal cells (BMSC). Methods. Pure platelet-rich plasma (P-PRP) and leukocyte-PRP (L-PRP) were characterized for platelet and leukocyte content. As an indicative marker of the delivery of growth factors (GFs), the release of basic fibroblast growth factor (bFGF) from platelet gel (PG) was measured at 1, 18, 48 and $72 \mathrm{~h}$ and at $7 \mathrm{~d}$. The ability of different PGs to induce proliferation and differentiation of BMSC was evaluated by using bioactivity assays. Results. The platelet recovery was significantly higher in L-PRP, either fresh or frozen. PGs derived from L-PRP and P-PRP showed significant differences in terms of bFGF release and biological activity. bFGF release was faster both in fresh and frozen L-PRP preparations. Moreover, L-PRP samples were able to induce a significantly higher proliferation of BMSC compared with P-PRP or PPP samples. Even though all PG preparations allowed the deposition of mineral nodules in BMSC cultures, the mineralization activity correlated significantly with bFGF levels. Conclusions. The biological activity of platelet concentrates differs according to preparation technique, which affects platelet and leukocyte content and GF availability. Because GF levels are not always optimal in subjects with defective bone healing, composition and bioactivity of PRP should be analyzed to test the reliability and potential effectiveness of the regenerative treatment.
\end{abstract}

Key Words: bone marrow stromal cells, osteogenesis, platelet gel, platelet-rich plasma

\section{Introduction}

Bone regeneration is a process in which a complex series of integrated events, which ultimately lead to bone healing, mostly depend on cells resident in bone and their surrounding microenvironment (1). Synergistic effects between mesenchymal stromal cells, growth factors (GFs), vascular structures, and extracellular matrix have been extensively demonstrated $(2,3)$. On the basis of this concept, one of the most studied approaches in bone regenerative medicine combines the use of GFs and osteogenic precursors. Bone marrow-derived stromal cells (BMSC) represent the most common source of osteogenic precursors used in bone-related clinical studies (4-6). Autologous blood concentrates, such as platelet-rich plasma (PRP), have been gaining popularity among orthopedic surgeons as a treatment modality for a variety of musculoskeletal injuries. It has been projected that the PRP market in the United States will be worth more than $\$ 120$ million by 2016 (7). The rationale for the use of PRP on bone lesions, which are hardly able to heal autonomously, is based on the significant reduction of endogenous GFs observed in nonunion sites (8). PRP may be used as a special source of GFs (9), mirroring what occurs physiologically after any bone injury, when platelets are

Correspondence: Francesca Perut, MSc, PhD, Laboratory for Orthopaedic Pathophysiology and Regenerative Medicine, Rizzoli Orthopedic Institute, Via di Barbiano 1/10, 40136 Bologna, Italy. E-mail: francesca.perut@ior.it 
entrapped in the native fracture hematoma. To be applied at the surgical site, PRP must be activated to induce platelet degranulation and fibrin polymerization, thus obtaining a clot usually called platelet gel (PG). PRP displays the unique characteristics of a mixture of bioactive molecules, and the regenerative potency of PRP probably depends on GF levels $(10,11)$. Pro-osteogenic factors, such as plateletderived growth factor, transforming growth factor- $\beta$, epidermal growth factor, vascular endothelial growth factor, insulin-like growth factors I and II and basic fibroblast growth factor (bFGF), play a pivotal role in bone regeneration, either alone or in combination with BMSC (12-15). However, despite two decades of clinical study, the efficacy of PG in bone healing is still under discussion because no accepted standard for its preparation is available $(7,16-18)$. The platelet concentration procedure is mainly based on blood centrifugation protocols (19), but the preparation technique and storage may influence composition and biological activity of PRP $(20,21)$.

The aim of this study was to investigate whether PRPs that differ in platelet concentration and in the presence or not of white blood cells may affect the osteogenic differentiation of BMSC. PRPs were prepared by two different techniques, namely a onestep procedure that is based on a clinically used commercial device (22) and a two-step procedure that is based on a previously described method (23). These two techniques are widely used in clinical practice and differ with regard to the resulting platelet concentration and leukocyte content. PRPs were characterized for platelet and white blood cell content. To track the GF delivery, as a representative marker we tested the bFGF released from PGs at different time points. We evaluated the relationship among the above parameters and the ability of PRP to induce the differentiation of osteogenic precursors in mature and functioning osteoblasts. Moreover, we evaluated whether or not the damage of leukocytes and platelets, which was induced by freezing and thawing of the concentrates, affected the osteogenic properties of PRP obtained with the two-step method (24).

\section{Methods}

\section{Subjects}

Ten healthy men (age range, 26-38 years), enrolled on a voluntary basis, underwent blood sample collection (200 mL per subject). Subjects did not present systemic disorders, infection, smoking habit, nonsteroidal anti-inflammatory drug use during the $5 \mathrm{~d}$ before blood donation, hemoglobin values $<11 \mathrm{~g} / \mathrm{dL}$ or platelet values $<150 \times 103 / \mu \mathrm{L}$. A code number was assigned to each sample to ensure subject anonymity.
The study was approved by the local ethics committee, and an informed written consent form was signed by each donor.

\section{Preparation of platelet concentrates}

For the pure platelet-rich plasma (P-PRP) one step method, a $45-\mathrm{mL}$ venous blood sample was divided into five tubes containing $1 \mathrm{~mL}$ of sodium citrate solution $(3.8 \%)$ and was then centrifuged ( $460 \mathrm{~g}$ for $8 \mathrm{~min}$ ); $1 \mathrm{~mL}$ per tube of the platelet-rich supernatant on the red blood cell pellet was then collected, with care taken to avoid leukocyte harvesting (22).

For the platelet leukocyte-rich plasma (L-PRP) two-step method, a 150-mL venous blood sample (25), collected in a bag containing $21 \mathrm{~mL}$ sodium citrate, was centrifuged ( $730 \mathrm{~g}$ for $15 \mathrm{~min}$ ). The resulting plasma and buffy-coat were transferred in a separate bag through a closed circuit, and red blood cells were eliminated. After centrifugation ( $3800 \mathrm{~g}$ for $10 \mathrm{~min}$ ), the supernatant was collected to produce L-PRP. During the second centrifugation step, poor platelet plasma (PPP) was collected and used as control. A half-volume of the L-PRP obtained was stored at $-30^{\circ} \mathrm{C}$ for $2 \mathrm{~h}$ and then thawed in a dry thermostat at $37^{\circ} \mathrm{C}$ for $30 \mathrm{~min}$ (fL-PRP) just before use. P-PRP, L-PRP, fL-PRP and PPP were activated with $10 \%$ $\mathrm{CaCl}_{2}(228 \mathrm{mmol} / \mathrm{L})$ to produce PGs.

\section{Platelet concentration and leukocyte number}

The platelet concentration and the white blood cell number were determined by blood cell count (COULTER LH 750 Hematology Analyzer; Beckman Coulter s.r.l, Milan, Italy). Linearity was $5-1000 \times 10^{3} / \mu \mathrm{L}$ for platelet count and $0.1-100 \times$ $10^{3} / \mu \mathrm{L}$ for white blood cell count.

\section{Evaluation of bFGF released from $P G$}

Each sample of PRP and PPP preparations was divided into five aliquots, activated with $10 \% \mathrm{CaCl}_{2}$ and incubated for $1,18,48$ and $72 \mathrm{~h}$ and $7 \mathrm{~d}$ at $37^{\circ} \mathrm{C}$ in $5 \% \mathrm{CO}_{2}$. The first time point of bFGF release was performed in agreement with the therapeutic schedule, taking into account that in clinical practice, the PRP injection is performed within $1 \mathrm{~h}$ from $\mathrm{CaCl}_{2}$ activation. The time course of bFGF release was aimed at evaluating the relationship with the functional results.

After centrifugation $\left(15 \mathrm{~min}\right.$ at $4000 \mathrm{rpm}$ at $20^{\circ} \mathrm{C}$ ), the supernatant was collected and frozen at $-30^{\circ} \mathrm{C}$ until use. Samples were assayed in duplicate and bFGF concentration was evaluated with the use of commercially available bead-based sandwich immunoassay kits (Bio-Rad Laboratories, Hercules, CA, USA) 
(26). Standard curve range was $0.07-18.366 \mathrm{pg} / \mathrm{mL}$, with an intra- and inter-assay coefficient of variability of $8 \%$. The immunocomplexes formed on distinct beads were quantified by use of the Bio-Plex Protein Array System (Bio-Rad Laboratories). Data were analyzed by use of the Bio-Plex Manager software version 6.0 (BioRad Laboratories). Standard levels between $70-130 \%$ of the expected values were considered accurate and were used. At least eight standards were accepted and used to establish standard curves, following a fiveparameter logistic regression model.

\section{BMSC cultures}

After approval by internal review boards, bone marrow samples were retrieved from discarded material collected during reconstructive hip surgery, and the resulting mononuclear cells were obtained as previously described (27). Isolated mononuclear cells were maintained in $\alpha$-minimum essential medium supplemented with $100 \mathrm{U} / \mathrm{mL}$ penicillin, $0.1 \mathrm{mg} / \mathrm{mL}$ streptomycin, and $100 \mu \mathrm{mol} / \mathrm{L}$ ascorbic acid-2 phosphate (Sigma-Aldrich, Milan, Italy) and $10 \%$ fetal bovine serum (Lonza, Milan, Italy). After $4 \mathrm{~d}$, nonadherent cells were removed and the culture was re-fed with fresh medium supplemented with $10^{-8} \mathrm{~mol} / \mathrm{L}$ dexamethasone (Sigma) (differentiation medium). At first confluence, cells expressed the typical surface antigens of BMSC (CD44, CD90,
CD105 and CD166) and a negligible expression of CD45 and CD117 (<1\%) (28). The mineralization ability was evaluated by culturing cells in mineralization medium containing $10 \mathrm{mmol} / \mathrm{L}$ $\beta$-glycerophosphate (Sigma) (13). In this study, a BMSC pool obtained from three male donors (age, 55,75 and $65 \mathrm{y}$ ), selected among 20 individuals on the basis of the ability of BMSC to form mineral nodules, was used (29).

\section{Characterization of the osteogenic properties of BMSC}

The protocol used for cell cultures and the time points selected to investigate the ability of PGs to induce osteoblast differentiation are reported in Figure 1. Cell viability and proliferation were assessed at the first confluence (T1, $6 \mathrm{~d}$ ) and at day 14 (T2) by the AlamarBlue test (Serotec Ltd, Oxford, UK) (Figure 1E,F). The mean of the relative fluorescence units measured on three wells was determined. The correlation between relative fluorescence units and cell number was linear, in the range of 5000-200,000 cells $(R=0.99)$, with intra- and inter-assay coefficient of variations of $8 \%$ (range, $1.8-16.3 \%$ ) and $11 \%$ (range, $0.7-20 \%$ ), respectively. The functional evaluation of the osteogenic properties was evaluated after $14 \mathrm{~d}$ of exposure to mineralization medium (Figure 1F) on duplicate wells, as previously described (30-32).
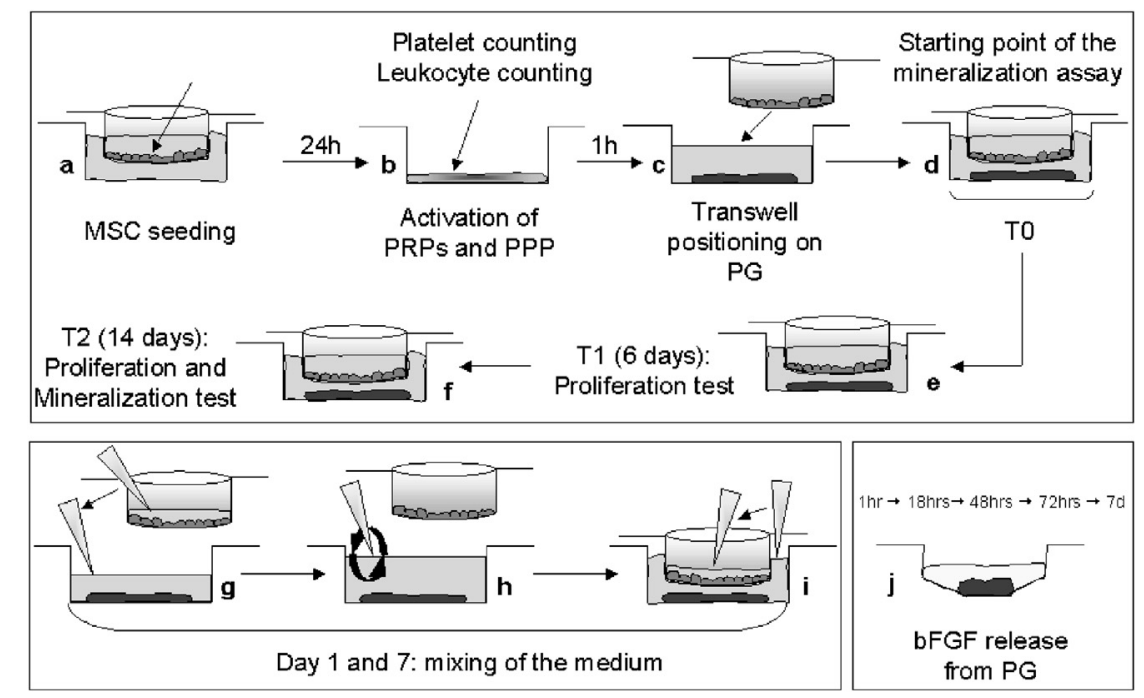

Figure 1. Schematic diagram of the culture protocol for investigating the ability of PG to induce osteoblast differentiation. (A) The BMSC pool was seeded onto the inserts of a 24 -transwell plate (pore size, $0.45 \mu \mathrm{m}$ ) at the density of $1 \times 104$ cells/well in differentiation medium and incubated for $24 \mathrm{~h}$ at $37^{\circ} \mathrm{C}$; (B) $108 \mu \mathrm{L}$ of different platelet concentrates and PPP as control were distributed in each well of a $24 /$ well plate and activated with $10 \% \mathrm{vol} / \mathrm{vol}$ of $\mathrm{CaCl}_{2}$ solution; (C, D) after $1 \mathrm{~h}$, the PG was formed and $480 \mu \mathrm{L}$ of serum-free differentiation medium was added to each well. The transwells pre-loaded with human MSCS were put over the PG, and $200 \mu \mathrm{L}$ of serum-free differentiation medium was added over the transwell; (E) at the first confluence (T1, $6 \mathrm{~d}$ ), cell viability and proliferation were assessed, and the medium was changed (F) while the mineralization assay was performed at T2 end point (14 d). (G-I) To favor the homogeneous distribution of the GFs released by the PG, at days 1 and 7, the supernatants of the upper and lower chambers of the transwell were mixed and redistributed in each compartment; $(J)$ for each type of $\mathrm{PG}$, five vials were incubated for $1,18,48$ and $72 \mathrm{~h}$ and $7 \mathrm{~d}$ at $37^{\circ} \mathrm{C}$. After centrifugation, supernatant was collected, and bFGF released was evaluated. 


\section{Statistical analysis}

Statistical analysis was performed by use of MedCalc Software 7.5.0.0 (Mariakerke, Belgium). Summary statistics were used to calculate mean, standard error of the mean, median and minimum-maximum values. The $\mathrm{D}^{\prime}$ Agostino-Pearson test was used to verify the normal distribution of analyzed parameters in the different subgroups. A nonparametric analysis of variance (Kruskal-Wallis test) was applied to detect the effects of the different platelet concentrates on the measured variables; the Mann-Whitney $U$ test was applied as a post hoc test if the $P$ value of the KruskalWallis test was $<0.05$. The Wilcoxon signed rank test was used in a paired analysis to verify the differences in bFGF release from PG at the different time points. The Spearman rank correlation coefficient $(R)$ was used to analyze the degree of association among the measured variables. All $P$ values $<0.05$ were considered statistically significant.

\section{Results}

Platelet recovery differs according to the preparation method of PRP

The number of platelets was significantly higher in all PRP preparations compared with PPP (Table I). The highest platelet recovery was obtained in the L-PRP preparation $(P<0.0001$ versus $f L-P R P, P-P R P$ and $\mathrm{PPP})$. The ratio between platelet number before and after concentration is significantly higher in L-PRP. Even though the preparation was the same as that used for L-PRP, in fL-PRP the platelet number was significantly reduced up to $65 \%$ (range, $31-89 \%$ ).
The two-step procedure determined effective platelet enrichment in all samples despite a wide variability, whereas the increment in platelet number was not always ensured with the one-step technique. Calcium chloride addition determined the gel formation in all samples, including PPP, demonstrated that platelet activation has been induced even if the platelet number was under the detection limit, as for PPP preparation. White blood cells were not found in P-PRP and PPP, whereas in L-PRP the mean number of leukocytes was comparable to the one of native blood (Table I). In L-PRP, the percentages of lymphocytes and polymorphonuclear cells (PMN) were $77.1 \% \pm$ $1.9 \%$ (range, $60-80 \%$; median, $81 \%$ ) and $21.9 \% \pm$ $1.9 \%$ (range, $12-40 \%$; median, $18.5 \%$ ), respectively. As observed for platelets, the leukocyte amount was significantly reduced after thawing of fL-PRP, thus proving that the freezing procedure was destructive for the cells. The number of leukocytes and platelets showed a significant correlation in both L-PRP preparations (L-PRP: $R=0.63$ and $P<0.0001$; fLPRP: $R=0.90$ and $P<0.0001)$.

Progressive release of bFGF from $P G$ varies according to the composition of PRP

The amount of bFGF increased significantly from $1 \mathrm{~h}$ to the final time point $(7 \mathrm{~d})$ in all samples (L-PRP, $P=0.005$; fL-PRP, $P=0.04$; P-PRP, $P<0.0004$; PPP, $P<0.001$ ) (Figure 2). A progressive increase was observed in P-PRP, which showed significant changes at each time point in comparison to the previous one, whereas the increase was more variable in L-PRP preparations, either fresh or thawed. The

Table I. Platelet concentration and leukocyte count in different PG preparations.

\begin{tabular}{|c|c|c|c|}
\hline & Platelet number, $10^{3} / \mu \mathrm{L}$ & $\begin{array}{l}\text { Ratio between platelet number after concentration } \\
\text { and platelet number in native blood }\end{array}$ & Leukocyte number, $10^{3} / \mu \mathrm{L}$ \\
\hline Native blood & $\begin{array}{c}202 \pm 55 \\
(163-258) \\
199\end{array}$ & NA & $\begin{array}{c}6.4 \pm 2.3 \\
(4.8-8.8) \\
5.9\end{array}$ \\
\hline L-PRP & $\begin{array}{l}920 \pm 491 \\
(555-1114)\end{array}$ & $\begin{array}{l}4.7 \pm 0.3 \\
(3.0-8.8)\end{array}$ & $\begin{array}{l}6.4 \pm 6.5 \\
(1.8-14.4)\end{array}$ \\
\hline & $\begin{array}{c}912 \\
P<0.0001 \text { vs fL-PRP, PRP, PPP }\end{array}$ & $\begin{array}{c}4.3 \\
P<0.0001 \text { vs } \mathrm{fL}-\mathrm{PRP}, \mathrm{PRP}, \mathrm{PPP}\end{array}$ & $\begin{array}{c}5.7 \\
P<0.0001 \text { vs fL-PRP, PRP, PPP }\end{array}$ \\
\hline fL-PRP & $\begin{array}{c}308 \pm 325 \\
(107-686) \\
238 \\
P<0.0001 \text { vs PPP }\end{array}$ & $\begin{array}{c}1.5 \pm 0.1 \\
(0.6-3.1) \\
1.2 \\
P<0.0001 \text { vs PPP }\end{array}$ & $\begin{array}{c}0.4 \pm 1.2 \\
(0.0-1.8) \\
0.0\end{array}$ \\
\hline P-PRP & $\begin{array}{c}260 \pm 37 \\
(83-738) \\
194 \\
P<0.0001 \text { vs PPP }\end{array}$ & $\begin{array}{c}1.2 \pm 0.2 \\
(0.5-3.3) \\
1.0 \\
P<0.0001 \text { vs PPP }\end{array}$ & 0.0 \\
\hline PPP & $\begin{array}{c}6.2 \pm 6.3 \\
(3-16) \\
5\end{array}$ & $\begin{array}{c}0.03 \pm 0.003 \\
(0.02-0.07) \\
0.03\end{array}$ & 0.0 \\
\hline
\end{tabular}

Data are expressed as mean \pm standard error of the mean (minimum-maximum values) and median. 


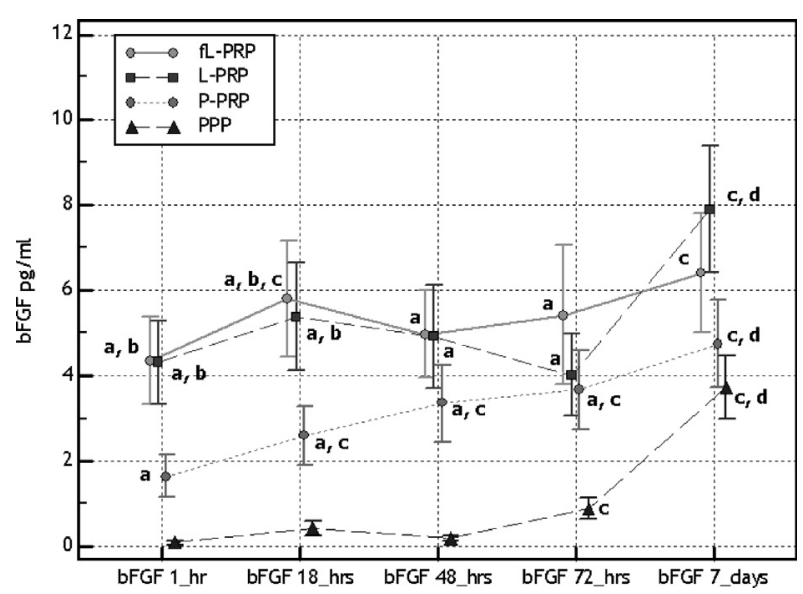

Figure 2. Graph shows the amount of bFGF $(\mathrm{pg} / \mathrm{mL})$ released by PG derived from different PRP preparations. (a,b) Significant difference in comparison to PPP and P-PRP, respectively $(P<$ 0.05, Mann-Whitney $U$ test); (c) significant difference in comparison to the previous time point; (d) significant change from $1 \mathrm{~h}$ to $7 \mathrm{~d}(P<0.05$, Wilcoxon signed rank test).

bFGF release from both L-PRPs was faster, because after $1 \mathrm{~h}$ and $18 \mathrm{~h}$, the concentration was significantly higher in comparison to P-PRP. Even though the bFGF amount was higher in PRP than in PPP, after day 7 , the differences disappeared because a considerable amount of this GF was found also in PPP. An inverse correlation was found between bFGF released from PG prepared with L-PRPs, either fresh or frozen, and platelet number at all time points (Table II). The inverse relationship was significant up to $18 \mathrm{~h}$ and at $72 \mathrm{~h}$. On the contrary, in P-PRP samples, the correlation between the platelet number and bFGF was always positive and became significant at $48 \mathrm{~h}$ up to $7 \mathrm{~d}$. A positive correlation was also found in PPP samples, and it was significant from $18 \mathrm{~h}$ forward. In PG obtained from L-PRP, the correlation between bFGF release and leukocyte number was also evaluated. An inverse relationship was found at all the time points, and it was significant at $1 \mathrm{~h}$ for $\mathrm{fL}-\mathrm{PRP}$ and at day 7 for L-PRP. Moreover, at all the time points, the number of PMN found in L-PRP correlated inversely with bFGF (Table II), whereas no significant correlation was found between bFGF and lymphocyte number (data not shown).

\section{BMSC proliferation is influenced by PRP composition and is significantly associated with $b F G F$ release}

As expected, the proliferation of BMSC increased from the seeding to the end point, with a log phase from $\mathrm{T} 0-\mathrm{T} 1$, and a stationary phase from $\mathrm{T} 1-\mathrm{T} 2$ (Figure 3). The type of PRPs influenced the yield of BMSC (Kruskal-Wallis $P$ value, T1: 0.002; T2: 0.001). The post hoc analysis revealed that L-PRPs were more effective than P-PRP in favoring cell proliferation, and a significant difference was found at T2 (L-PRP versus $\mathrm{P}-\mathrm{PRP}, P=0.014$; $\mathrm{fL}-\mathrm{PRP}$ versus P-PRP, $P=0.027)$. The proliferation rate induced by PPP was similar to that observed with PRPs, but the cell number at $\mathrm{T} 1$ and $\mathrm{T} 2$ was significantly lower in comparison to L-PRPs (L-PRP versus PPP, $P=0.004$ at T1 and $P=0.001$ at T2; fL-PRP versus PPP, $P=$ 0.0003 at $\mathrm{T} 1$ and $P=0.002$ at T2).

We analyzed the association between cell proliferation in the exponential phase of growth, for example, up to $\mathrm{T} 1$, and concentration of the blood components in different PGs (Table III). A significant, positive correlation was found between BMSC proliferation and number of platelets in cultures exposed to PG derived from P-PRP and PPP; on the contrary, a significant, negative correlation was found when BMSC were cultured with fresh L-PRP. The BMSC proliferation was significantly correlated with the amount of bFGF released from all PG samples during $7 \mathrm{~d}$.

As expected, BMSC proliferation in the steady state of growth, that is, up to T2, was poorly influenced by leukocyte and platelet number present in both L-PRPs (data not shown), whereas the positive

Table II. Correlation between bFGF released from PG and number of platelets and leukocytes after concentration procedure.

\begin{tabular}{|c|c|c|c|c|c|}
\hline & \multicolumn{5}{|c|}{ bFGF } \\
\hline & $1 \mathrm{~h}$ & $18 \mathrm{~h}$ & $48 \mathrm{~h}$ & $72 \mathrm{~h}$ & $7 \mathrm{~d}$ \\
\hline \multicolumn{6}{|l|}{ L-PRP } \\
\hline No. of platelets & $-0.50(0.009)$ & $-0.61(0.0006)$ & $-0.46(0.011)$ & $-0.49(0.006)$ & $-0.22(0.238)$ \\
\hline No. of leukocytes & $-0.13(0.489)$ & $-0.20(0.261)$ & $-0.15(0.405)$ & $-0.25(0.179)$ & $-0.59(0.002)$ \\
\hline No. of PMN & $-0.44(0.009)$ & $-0.42(0.0057)$ & $-0.38(0.0009)$ & $-0.37(0.0014)$ & $0.59(0.0003)$ \\
\hline \multicolumn{6}{|l|}{ fL-PRP } \\
\hline No. of platelets & $-0.60(0.0009)$ & $-0.45(0.012)$ & $-0.25(0.164)$ & $-0.46(0.010)$ & $-0.17(0.370)$ \\
\hline No. of leukocytes & $-0.39(0.028)$ & $-0.23(0.197)$ & $-0.09(0.606)$ & $-0.13(0.463)$ & $-0.18(0.352)$ \\
\hline \multicolumn{6}{|l|}{ P-PRP } \\
\hline No. of platelets & $0.30(0.090)$ & $0.30(0.097)$ & $0.37(0.030)$ & $0.38(0.033)$ & $0.37(0.039)$ \\
\hline \multicolumn{6}{|l|}{ PPP } \\
\hline No. of platelets & $0.29(0.102)$ & $0.63(0.0005)$ & $0.62(0.0006)$ & $0.66(0.0003)$ & $0.52(0.004)$ \\
\hline
\end{tabular}

Spearman $R$ and $P$ values are shown in parentheses. 


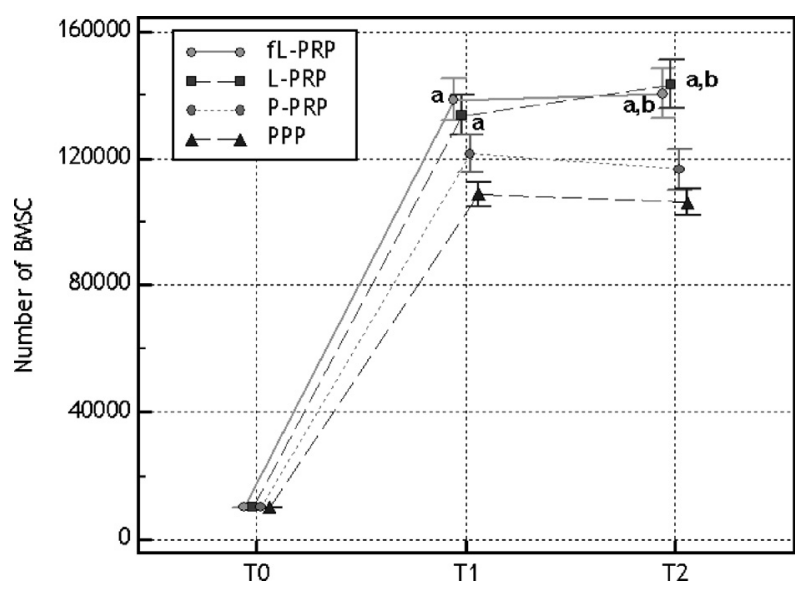

Figure 3. Number of BMSC retrieved after 6 (T1) and 14 (T2) d of culture with different PG preparation. A significant difference in comparison to PPP (a) and to P-PRP (b) was found $(P<0.05$, Mann-Whitney $U$ test).

and significant correlation with P-PRP was maintained $(R=0.52, P=0.004)$. No correlation was found between bFGF amount and cell recovery at $\mathrm{T} 2$.

\section{Mineralization ability of BMSC is significantly associated with $b F G F$ release}

Cell mineralization was always detectable irrespective of the source of PG, including that obtained from PPP. The number and the size of calcium phosphate deposits obtained with the use of PG from different individuals were variable. A qualitative analysis of mineral nodule formation revealed a more effective ability of L-PRP and fL-PRP to induce osteoblast differentiation, compared with the other samples (Figure 4). However, the Alizarin red stain quantification did not show any significant difference between PG preparation and/or PPP samples (Figure 5).

In L-PRP, either fresh or frozen, the ability of BMSC to mineralize was not influenced by platelet number, whereas a positive significant correlation was found with the platelet amount recovered in P-PRP and PPP samples (Table IV). In all cases, the bFGF released during the first $72 \mathrm{~h}$ showed a significant positive correlation with the mineralization ability of BMSC. After $7 \mathrm{~d}$, the positive relationship persisted only with fL-PRP and P-PRP. In addition, a strong association was found between mineralization ability and number of BMSC recovered at T1 (L-PRP, $R=0.71$; fL-PRP, $R=0.73$; P-PRP, $R=0.65$; PPP, $R=0.70 ; P<0.0001$ for all samples).

\section{Discussion}

In this study, we demonstrate that the ability of different PGs to induce proliferation and osteogenic differentiation of BMSC is related to PRP features, including platelet and leukocyte content and GF availability.

The highest platelet yield was obtained in fresh L-PRP samples, and the difference in terms of platelet recovery between L-PRP and fL-PRP or P-PRP was highly significant. It is reasonable to assume that a more selective process aimed to remove leukocytes, for example, the procedure to obtain P-PRP, translates into a lower platelet recovery. It is noteworthy that the platelet enrichment was always obtained when the L-PRP method was used, even with a wide variability among donors, whereas the platelet enrichment was not guaranteed with the P-PRP technique. That is not surprising because the two-step method allows the recovery of platelets that have not been fully concentrated after the first centrifugation. Other authors observed that some individuals can have a complete failure to concentrate platelets with one method but are successful in concentrating platelets with alternative systems (19). Previous investigators have defined the efficacy of PRP according to platelet concentration. Generally, a concentration ranging from $200-1000 \times 10^{3}$ platelets $/ \mathrm{mL}$ is considered effective for tissue healing, whereas higher counts appear to be biologically unfavorable (19). In our hands, platelet amounts $>1000 \times 10^{3} / \mathrm{mL}$ were obtained in two cases treated with the two-step procedure, whereas in five of $10 \mathrm{P}-\mathrm{PRP}$, the platelet recovery was $<200 \times 10^{3} / \mathrm{mL}$.

It has been demonstrated that the composition of PRP influences the release of the most relevant GFs,

Table III. Correlation between BMSC proliferation at T1 in cultures exposed to different PG (first row) and variables measured in PRPs (first column).

\begin{tabular}{lcccc}
\hline & L-PRP & fL-PRP & P-PRP & PPP \\
\hline No. of platelets in PRP & $-0.71(<0.0001)$ & $-0.32(0.080)$ & $0.79(<0.0001)$ & $0.37(0.039)$ \\
No. of leukocytes in PRP & $-0.02(0.880)$ & $-0.38(0.033)$ & NA & NA \\
bFGF 1 h & $0.75(<0.0001)$ & $0.70(<0.0001)$ & $0.51(0.004)$ & $0.19(0.283)$ \\
bFGF 18 h & $0.85(<0.0001)$ & $0.84(<0.0001)$ & $0.44(0.010)$ & $0.46(0.010)$ \\
bFGF 48 h & $0.84(<0.0001)$ & $0.82(<0.0001)$ & $0.60(0.0009)$ & $0.76(<0.0001)$ \\
bFGF 72 h & $0.84(<0.0001)$ & $0.78(<0.0001)$ & $0.50(0.005)$ & $0.86(<0.0001)$ \\
bFGF 7 d & $0.84(<0.0001)$ & $0.78(<0.0001)$ & $0.50(0.005)$ & $0.86(<0.0001)$ \\
\hline
\end{tabular}

Spearman $R$ and $P$ values are shown in parentheses. 

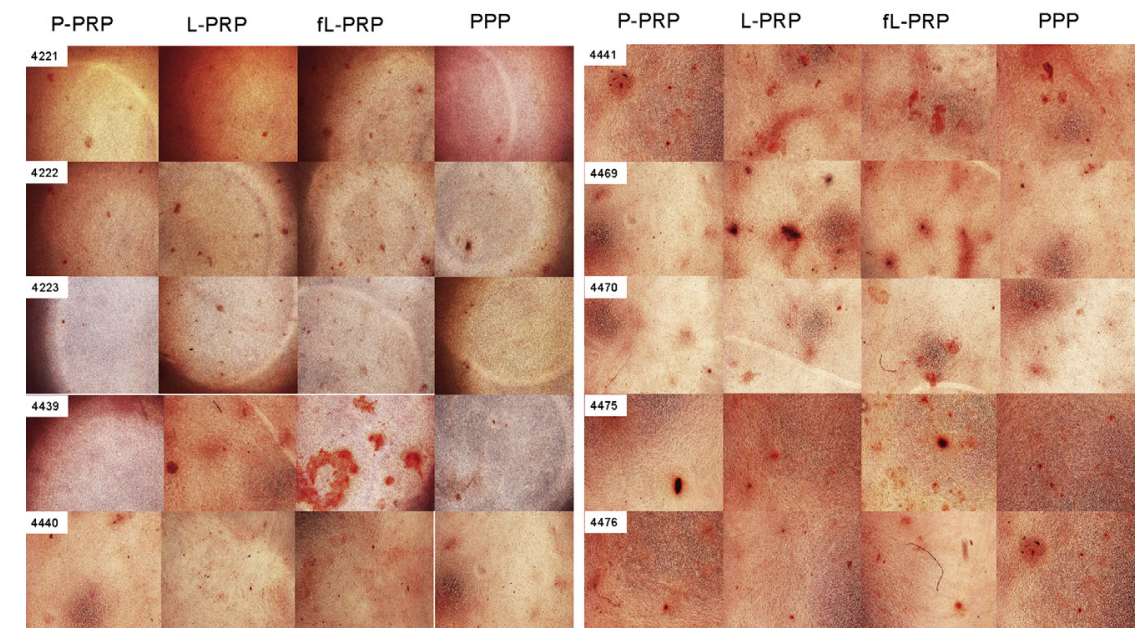

Figure 4. Mineralization assay. PGs from different individuals (lab code at top left) were able to induce the formation of mineral nodules irrespective of the preparation method of PRP (magnification $\times 4$ ).

but no data are available on the optimal amount of osteogenic factors contained in PGs and on their mutual relationship in terms of efficacy $(10,33)$. Among the variety of GFs released from PG, as a representative marker we chose to test bFGF. It is obvious that bFGF cannot be considered the unique factor to explain the potency of different PG preparations but could be an adequate reference to predict the ability of autologous PRP to induce osteoblast differentiation. Indeed, a close interconnection between the release of bFGF and other osteogenic GFs has been demonstrated $(19,34)$. bFGF is actively involved in osteogenesis and angiogenesis (35-37). Recombinant bFGF has been used for supporting BMSC expansion, and it is able to induce an abundant calcium deposition (38). Preclinical investigations suggest that bFGF may be useful to promote bone healing $(39,40)$. The use of recombinant bFGF after nailing of tibial fractures

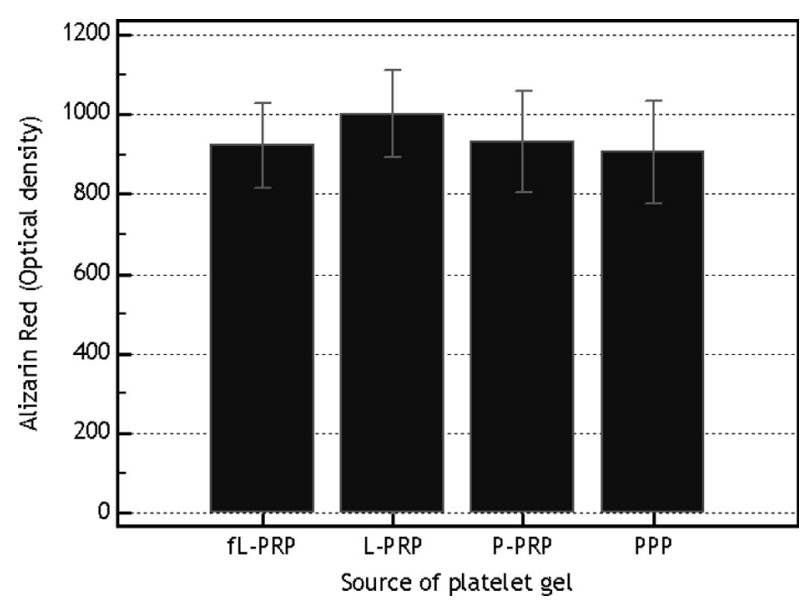

Figure 5. Mineralization assay. Histograms show quantitative analysis of the Alizarin red staining (mean \pm standard error of the mean) obtained with the different platelet preparations. significantly favors fracture healing (41), and, recently, we demonstrated that bFGF circulating level predicts the outcome of a severe bone lesion (31). The absolute concentration of bFGF increased significantly from $1 \mathrm{~h}$ to $7 \mathrm{~d}$ in all samples. Both L-PRPs exhibited a variable and discontinuous release of GFs. Nevertheless, the release was more prompt because at 1-h and 18-h time points, bFGF levels were significantly higher than that measured in P-PRP. Interestingly, after $7 \mathrm{~d}$, the bFGF release from the clot obtained with PPP was similar to that observed in the other samples. GFs released from PG basically derive from activated platelets but also from plasma, for example, circulating GFs. We may reasonably assume that the amount of bFGF detected in PPP corresponds mainly to the plasma circulating GF (42), because the number of platelets detected in the PPP preparation was very low, that is, close to or under the detection limit.

On the contrary, bFGF measured in PRPs derives largely from activated platelets and strictly depends on their number, and the circulating level of GFs represents only a marginal part of the total amount. According to this hypothesis, at the early time points we found that bFGF was significantly higher in samples with a higher platelet content, for example, L-PRPs, even though these differences disappeared after $7 \mathrm{~d}$. A positive correlation between platelet number and bFGF amount was found only in P-PRP and in PPP, even if in the latter the platelet number was very low. Unexpectedly, despite the higher platelet content, a negative correlation between platelet number and bFGF amount was detected in L-PRP samples, either fresh or thawed. One possible explanation for this discrepancy may be the presence of leukocytes, that is, the more numerous they are, the more the bFGF release could be hindered even if the basal amount is very high. Other authors have shown 
Table IV. Correlation between Alizarin red staining in cultures exposed to different PG (first row) and variables measured in PRP (first column).

\begin{tabular}{lcccc}
\hline & L-PRP & \multicolumn{1}{c}{ fL-PRP } & P-PRP & PPP \\
\hline No. of platelets in PRP & $-0.32(0.074)$ & $-0.29(0.105)$ & $0.50(0.005)$ & $0.53(0.004)$ \\
No. of leukocytes in PRP & $-0.21(0.240)$ & $-0.22(0.216)$ & NA & NA \\
bFGF 1 h & $0.56(0.003)$ & $0.72(<0.0001)$ & $0.62(0.0005)$ & $0.17(0.350)$ \\
bFGF 18 h & $0.70(<0.0001)$ & $0.81(<0.0001)$ & $0.57(0.002)$ & $0.38(0.036)$ \\
bFGF 48 h & $0.64(0.0004)$ & $0.78(<0.0001)$ & $0.65(0.0003)$ & $0.61(0.0008)$ \\
bFGF 72 h & $0.63(0.0005)$ & $0.76(<0.0001)$ & $0.61(0.0006)$ & $0.75(<0.0001)$ \\
bFGF 7 d & $0.22(0.217)$ & $0.67(0.004)$ & $0.71(<0.0001)$ & $0.08(0.662)$ \\
\hline
\end{tabular}

Spearman $R$ and $P$ values are shown in parentheses.

that the GF release varies according to PRP preparation and is influenced by the presence of white blood cells and the architecture of the fibrin network (33). Because P-PRP and L-PRP exhibit a similar pattern of fibrin organization, we can hypothesize that leukocytes play a crucial role in GF spreading. It has been recently demonstrated that PMN from healthy individuals express different levels of FGF receptors in their cytosol (FGFR-1 and FGFR-4) and cytoplasmic membrane (FGFR-2) (43). These receptors may capture bFGF, therefore explaining the inverse relation between $\mathrm{bFGF}$ and PMN number in L-PRP samples at all time points. In addition, PRP concentrates containing lymphocytes can sustain the production of new bFGF after the initial release (44). The effect of leukocytes is still controversial and could be either positive or negative, depending on tissue and/ or underlying disease. Some authors have demonstrated that the presence of PMN can result in proinflammatory cell signaling and local tissue catabolism (45-47), whereas others have shown that macrophages are essential for debridement of damaged ligamentous tissue and for cytokine release mediating the repair process (48). For this reason, the manufacturing procedure of PG and the relative presence of leukocytes must be thoroughly investigated.

To better understand the PG "potency," the proosteogenic activity may be evaluated by means of a bioactivity assay. We previously demonstrated that the in vitro mineralization assay is a reliable tool to evaluate the activity of the whole GF system in its complexity more effectively than other biochemical, functional and molecular assays (30). Moreover, the correlation between in vitro mineralization test and regenerative ability has been demonstrated in other experimental models (49).

In the log phase, proliferation of BMSC is significantly different, according to the composition of PRP. The highest number of platelets and the most abundant release of $b F G F$ positively influence BMSC proliferation. In fact, it is higher in cells treated with L-PRP or fL-PRP, thus suggesting that the presence of leukocytes does not affect proliferation of target cells. The positive correlation that was found between
bFGF and cell number at T1 confirms that GF availability plays a pivotal role in supporting the expansion of osteogenic precursors $(37,50)$. Although PPP could promote cell proliferation when it is activated, the effect was lower than that of PRPs in this study and some other studies (10).

The mineralization ability of different PGs was similar irrespective of the preparation method of PRP and was observed also in cells cultured with PPP. L-PRP appeared to be more active in inducing osteoblast differentiation, even though the quantitative analysis of the mineral matrix deposition did not show significant differences. Once again, the bFGF released from PG was strictly related to the mineralization ability of BMSC, and this direct relationship was observed with all the preparations, including the one derived from PPP. Because bFGF detected in PPP samples is reasonably derived from circulating bFGF, we can hypothesize that GF availability in the serum could influence the PG bioactivity and that this aspect should be carefully considered. In fact, it has been demonstrated that autologous serum with low bFGF levels $(<4 \mathrm{pg} / \mathrm{mL})$ is not able to induce the mineralization of BMSC, whereas deposition of mineral nodules occurs if cells are treated with homologous sera containing high levels of bFGF $(>10 \mathrm{pg} / \mathrm{mL})(31)$.

We performed freezing and thawing of L-PRP samples to evaluate whether the damage of leukocytes and platelets could affect the ability of L-PRP to induce osteoblast differentiation. Repeated shortterm freezing and thawing are sometimes used to damage platelet membranes and to cause extensive degranulation to increase GF content in PRP (51). In our hands, the procedure reduced platelet and leukocyte number but did not affect the GFs release, as shown by comparable levels of bFGF detected in L-PRP and fL-PRP samples. Accordingly, proliferation of BMSC and mineralization were similar in cells treated with L-PRP or fL-PRP.

In conclusion, we found that the method of PRP preparation influences not only platelet and leukocyte content but also GF release and the ability of PRP to induce osteoblast differentiation. Experimental evidence shows that L-PRP is more effective 
to reach a high bFGF concentrations and stimulate the proliferation of osteogenic precursors. Fresh and frozen L-PRP show similar biological activities, thus suggesting that PG cryopreservation should be regarded as a safe procedure that does not affect the final properties of platelet concentrate and allows an adequate quality control of the product. The mineralization ability of osteogenic precursors is related to GF levels. Because the GF levels might not always be optimal in subjects with defective bone healing, composition and bioactivity of PRP should be analyzed every time, so that a clinician may have an additional assurance on the reliability and potential effectiveness of the regenerative treatment.

\section{Acknowledgments}

This study was supported by grants from the Italian Ministry of the Health, "5 per mille" 2009 (DG, NB and EM) and partially supported by grants from Bologna University, RFO fund (EM and AF); EU Project ADIPOA, contract No. 241719 (EM and $\mathrm{AF}$ ); FIRB RBAP10KCNS fund (EM and AF); and Italian Health Ministry: "Platelet Rich Plasma, From Clinical Application to Research and Back: A New Non-Surgical Bioactive Treatment for Knee Cartilage Degeneration and Osteoarthritis” (EK).

Disclosure of interest: The authors have no commercial, proprietary, or financial interest in the products or companies described in this article.

\section{References}

1. Arvidson $\mathrm{K}$, Abdallah BM, Applegate LA, Baldini N, Cenni E, Gomez-Barrena E, et al. Bone regeneration and stem cells. J Cell Mol Med. 2011;15:718-46.

2. Augello A, Kurth TB, De Bari C. Mesenchymal stem cells: a perspective from in vitro cultures to in vivo migration and niches. Eur Cell Mater. 2010;20:121-33.

3. Kim SH, Turnbull J, Guimond S. Extracellular matrix and cell signalling: the dynamic cooperation of integrin, proteoglycan and growth factor receptor. J Endocrinol. 2011;209: 139-51.

4. Hernigou P, Poignard A, Manicom O, Mathieu G, Rouard H. The use of percutaneous autologous bone marrow transplantation in nonunion and avascular necrosis of bone. J Bone Joint Surg Br. 2005;87:896-902.

5. Jäger M, Jelinek EM, Wess KM, Scharfstädt A, Jacobson M, Kevy SV, et al. Bone marrow concentrate: a novel strategy for bone defect treatment. Curr Stem Cell Res Ther. 2009;4: $34-43$.

6. Chanda D, Kumar S, Ponnazhagan S. Therapeutic potential of adult bone marrow-derived mesenchymal stem cells in diseases of the skeleton. J Cell Biochem. 2010;111:249-57.

7. Sheth U, Simunovic N, Klein G, Fu F, Einhorn TA, Schemitsch E, et al. Efficacy of autologous platelet-rich plasma use for orthopaedic indications: a meta-analysis. J Bone Joint Surg Am. 2012;94:298-307.
8. Gandhi A, Bibbo C, Pinzur M, Lin SS. The role of plateletrich plasma in foot and ankle surgery. Foot Ankle Clin. 2005; 10:621-37.

9. Anitua E, Andia I, Ardanza B, Nurden P, Nurden AT. Autologous platelets as a source of proteins for healing and tissue regeneration. Thromb Haemost. 2004;91:4-15.

10. Boswell SG, Cole BJ, Sundman EA, Karas V, Fortier LA. Platelet-rich plasma: a milieu of bioactive factors. Arthroscopy. 2012;28:429-39.

11. Cho HS, Song IH, Park SY, Sung MC, Ahn MW, Song KE. Individual variation in growth factor concentrations in platelet-rich plasma and its influence on human mesenchymal stem cells. Korean J Lab Med. 2011;31:212-8.

12. Intini $G$. The use of platelet-rich plasma in bone reconstruction therapy. Biomaterials. 2009;30:4956-66.

13. Cenni E, Perut F, Ciapetti G, Savarino L, Dallari D, Cenacchi $\mathrm{A}$, et al. In vitro evaluation of freeze-dried bone allografts combined with platelet rich plasma and human bone marrow stromal cells for tissue engineering. J Mater Sci Mater Med. 2009;20:45-50.

14. Janicki P, Schmidmaier G. What should be the characteristics of the ideal bone graft substitute? Combining scaffolds with growth factors and/or stem cells. Injury. 2011;42:S77-81.

15. Cenni E, Savarino L, Perut F, Fotia C, Avnet S, Sabbioni G. Background and rationale of platelet gel in orthopaedic surgery. Musculoskel Surg. 2010;94:1-8.

16. Bielecki T, Gazdzik TS, Szczepanski T. Benefit of percutaneous injection of autologous platelet-leukocyte-rich gel in patients with delayed union and nonunion. Eur Surg Res. 2008;40:289-96.

17. Kawasumi $\mathrm{M}$, Kitoh $\mathrm{H}$, Siwicka KA, Ishiguro $\mathrm{N}$. The effect of the platelet concentration in platelet-rich plasma gel on the regeneration of bone. J Bone Joint Surg Br. 2008;90: 966-72.

18. Kazakos K, Lyras DN, Thomaidis V, Agrogiannis G, Botaitis S, Drosos G, et al. Application of PRP gel alone or in combination with guided bone regeneration does not enhance bone healing process: an experimental study in rabbits. J Craniomaxillofac Surg. 2011;39:49-53.

19. Mazzocca AD, McCarthy MB, Chowaniec DM, Cote MP, Romeo AA, Bradley JP, et al. Platelet-rich plasma differs according to preparation method and human variability. J Bone Joint Surg Am. 2012;94:308-16.

20. Dohan Ehrenfest DM, Rasmusson L, Albrektsson T. Classification of platelet concentrates: from pure platelet-rich plasma (P-PRP) to leucocyte- and platelet-rich fibrin (LPRF). Trends Biotechnol. 2009;27:158-67.

21. Tschon $M$, Fini $M$, Giardino R, Filardo G, Dallari $D$, Torricelli $\mathrm{P}$, et al. Lights and shadows concerning platelet products for musculoskeletal regeneration. Front Biosci (Elite Ed). 2011;3:96-107.

22. Anitua E, Orive G, Aguirre JJ, Andía I. Five-year clinical evaluation of short dental implants placed in the posterior areas: a retrospective study. J Periodontal. 2008;79:42-8.

23. Kon E, Mandelbaum B, Buda R, Filardo G, Delcogliano M, Timoncini A, et al. Platelet-rich plasma intra-articular injection versus hyaluronic acid viscosupplementation as treatments for cartilage pathology: from early degeneration to osteoarthritis. Arthroscopy. 2011;27:1490-501.

24. Takahashi T, Hammett MF, Cho MS. Multifaceted freezing injury in human polymorphonuclear cells at high subfreezing temperatures. Cryobiology. 1985;22:215-36.

25. Filardo G, Kon E, Buda R, Timoncini A, Di Martino A, Cenacchi A, Fornasari PM, Giannini S, Marcacci M. Plateletrich plasma intra-articular knee injections for the treatment of degenerative cartilage lesions and osteoarthritis. Knee Surg Sports Traumatol Arthrosc. 2011;4:528-35. 
26. Mariani E, Cattini L, Neri S, Malavolta M, Mocchegiani E, Ravaglia G, et al. Simultaneous evaluation of circulating chemokine and cytokine profiles in elderly subjects by multiplex technology: relationship with zinc status. Biogerontology. 2006;7:449-59.

27. Ciapetti G, Ambrosio L, Marletta G, Baldini N, Giunti A. Human bone marrow stromal cells: in vitro expansion and differentiation for bone engineering. Biomaterials. 2006;27: 6150-60.

28. Dominici M, Le Blanc K, Mueller I, Slaper-Cortenbach I, Marini F, Krause D, et al. Minimal criteria for defining multipotent mesenchymal stromal cells: the International Society for Cellular Therapy position statement. Cytotherapy. 2006;8:315-7.

29. Leonardi E, Devescovi V, Perut F, Ciapetti G, Giunti A. Isolation, characterisation and osteogenic potential of human bone marrow stromal cells derived from the medullary cavity of the femur. Chir Organi Mov. 2008;92:97-103.

30. Granchi D, DeVescovi V, Baglio SR, Magnani M, Donzelli O, Baldini N. Regenerative approach for bone repair in congenital pseudarthrosis: correlation between laboratory findings and clinical outcome. Cytotherapy. 2012;14:306-14.

31. Granchi D, Devescovi V, Pratelli L, Verri E, Magnani M, Donzelli $\mathrm{O}$, et al. Serum levels of fibroblast growth factor 2 in children with orthopedic diseases: potential role in predicting bone healing. J Orthop Res. 2013;31:249-56.

32. Lohmann $M$, Walenda $G$, Hemeda $H$, Joussen $S$, Drescher W, Jockenhoevel S, et al. Donor age of human platelet lysate affects proliferation and differentiation of mesenchymal stem cells. PLoS One. 2012;7:e37839.

33. Dohan Ehrenfest DM, Bielecki T, Jimbo R, Barbé G, Del Corso $\mathrm{M}$, Inchingolo $\mathrm{F}$, et al. Do the fibrin architecture and leukocyte content influence the growth factor release of platelet concentrates? An evidence-based answer comparing a pure platelet-rich plasma (P-PRP) gel and a leukocyte- and platelet-rich fibrin (L-PRF). Curr Pharm Biotechnol. 2012; 13:1145-52.

34. Weiss S, Zimmermann G, Pufe T, Varoga D, Henle P. The systemic angiogenic response during bone healing. Arch Orthop Trauma Surg. 2009;129:989-97.

35. Montero A, Okada Y, Tomita M, Ito M, Tsurukami $\mathrm{H}$, Nakamura T, et al. Disruption of the fibroblast growth factor2 gene results in decreased bone mass and bone formation. J Clin Invest. 2000;105:1085-93.

36. Presta M, Dell'Era P, Mitola S, Moroni E, Ronca R, Rusnati M. Fibroblast growth factor/fibroblast growth factor receptor system in angiogenesis. Cytokine Growth Factor Rev. 2006;16:159-78.

37. Hughes-Fulford M, Li CF. The role of bFGF and BMP-2 in regulation of gene induction, cell proliferation and mineralization. J Orthop Surg Res. 2011;9:6-8.

38. Martin I, Muraglia A, Campanile G, Cancedda R, Quarto R. Fibroblast growth factor-2 supports ex vivo expansion and maintenance of osteogenic precursors from human bone marrow. Endocrinology. 1997;138:4456-62.

39. Chen WJ, Jingushi S, Aoyama I, Anzai J, Hirata G, Tamura M, et al. Effects of FGF-2 on metaphyseal fracture repair in rabbit tibiae. J Bone Miner Metab. 2004;22: 303-9.

40. Radomsky ML, Aufdemorte TB, Swain LD, Fox WC, Spiro RC, Poser JW. A novel formulation of FGF-2 in a hyaluronan gel accelerates fracture healing in non-human primates. J Orthop Res. 1999;17:607-14.

41. Kawaguchi $\mathrm{H}$, Oka $\mathrm{H}$, Jingushi S, Izumi $\mathrm{T}$, Fukunaga $\mathrm{M}$, Sato K, et al. A local application of recombinant human fibroblast growth factor 2 for tibial shaft fractures: a randomized, placebo-controlled trial. J Bone Miner Res. 2010;25: 2735-43.

42. Clendenen TV, Arslan AA, Lokshin AE, Idahl A, Hallmans G, Koenig KL, et al. Temporal reliability of cytokines and growth factors in EDTA plasma. BMC Res Notes. 2010;3:302-11.

43. Haddad LE, Khzam LB, Hajjar F, Merhi Y, Sirois MG. Characterization of FGF receptor expression in human neutrophils and their contribution to chemotaxis. Am J Physiol Cell Physiol. 2011;301:C1036-45.

44. Blotnick S, Peoples GE, Freeman MR, Eberlein TJ, Klagsbrun M. T lymphocytes synthesize and export heparinbinding epidermal growth factor-like growth factor and basic fibroblast growth factor, mitogens for vascular cells and fibroblasts: differential production and release by CD4+ and CD8+ T cells. Proc Natl Acad Sci U S A. 1994;91:2890-4.

45. Jacobsen LC, Sørensen OE, Cowland JB, Borregaard N, Theilgaard-Mönch $\mathrm{K}$. The secretory leukocyte protease inhibitor (SLPI) and the secondary granule protein lactoferrin are synthesized in myelocytes, colocalize in subcellular fractions of neutrophils, and are coreleased by activated neutrophils. J Leukoc Biol. 2008;83:1155-64.

46. McCarrel T, Fortier L. Temporal growth factor release from platelet-rich plasma, trehalose lyophilized platelets, and bone marrow aspirate and their effect on tendon and ligament gene expression. J Orthop Res. 2009;27:1033-42.

47. Sundman EA, Cole BJ, Fortier LA. Growth factor and catabolic cytokine concentrations are influenced by the cellular composition of platelet-rich plasma. Am J Sports Med. 2011; 39:2135-40.

48. Chamberlain CS, Leiferman EM, Frisch KE. The influence of macrophage depletion on ligament healing. Connect Tissue Res. 2011;52:203-11.

49. De Bari C, Dell'Accio F, Karystinou A, Guillot PV, Fisk NM, Jones EA, et al. A biomarker-based mathematical model to predict bone-forming potency of human synovial and periosteal mesenchymal stem cells. Arthritis Rheum. 2008;58: 240-50.

50. Yamachika E, Tsujigiwa H, Matsubara M, Hirata $Y$, Kita K, Takabatake K, et al. Basic fibroblast growth factor supports expansion of mouse compact bone-derived mesenchymal stem cells (MSCs) and regeneration of bone from MSC in vivo. J Mol Histol. 2012;43:223-33.

51. Zimmermann R, Arnold D, Strasser E, Ringwald J, Schlegel A, Wiltfang J, et al. Sample preparation technique and white cell content influence the detectable levels of growth factors in platelet concentrates. Vox Sang. 2003;85: 283-9. 